\title{
Residual pulmonary hypertension after pulmonary endarterectomy: What is there more than meets the eye?
}

\author{
Giovanni Battista Luciani, MD
}

\footnotetext{
From the Division of Cardiac Surgery, Department of Surgery, Dentistry, Pediatrics and Obstetrics/Gynecology, University of Verona, Verona, Italy.

Disclosures: Author has nothing to disclose with regard to commercial support.

Received for publication May 19, 2018; revisions received May 19, 2018; accepted for publication May 21, 2018; available ahead of print June 28, 2018.

Address for reprints: Giovanni Battista Luciani, MD, Division of Cardiac Surgery, Department of Surgery, Dentistry, Pediatrics and Obstetrics/Gynecology, University of Verona, O. C. M. Piazzale Stefani 1, Verona, 37126 Italy (E-mail: giovanni.luciani@univr.it).

J Thorac Cardiovasc Surg 2018;156:1288-9

$0022-5223 / \$ 36.00$

Copyright (c) 2018 by The American Association for Thoracic Surgery

https://doi.org/10.1016/j.jtcvs.2018.05.072
}

The meta-analysis by Hsieh and colleagues ${ }^{1}$ in this issue of the Journal addresses residual pulmonary hypertension $(\mathrm{PH})$, a taxing problem after pulmonary endarterectomy in patients with chronic thromboembolic pulmonary hypertension (CTEPH). ${ }^{2}$ Whereas diagnostic criteria for CTEPH and indication for surgical treatment have since been established, leading to outstanding success rates of treatment in experienced units and durable clinical improvement in the majority of patients, ${ }^{2}$ persistence or recurrence of $\mathrm{PH}$ is emerging as a worrisome sequela in as many as 1 in 4 late survivors.

The study by Hsieh and colleagues ${ }^{1}$ has the merit of applying rather strict selection criteria, including assessment of clinical (6-minute walking distance) and hemodynamic (pulmonary artery pressure and vascular resistance) outcomes in the follow-up. Whereas the yield of metaanalysis is expectedly low and significant heterogeneity remains in the quantification of residual $\mathrm{PH}$, most selected studies agree on the observation that pulmonary endarterectomy has the potential for decreasing pulmonary artery pressure and vascular resistance even in patients who display persistent $\mathrm{PH}$ after surgery. This is by far the most important output of the analysis by Hsieh and colleagues. ${ }^{1}$ The clinical relevance of this hemodynamic result is perhaps less predictable, as increase in 6-minute walking is reported in less than one half of the studies and New York Heart Association/World Health Organization improvement only in one fourth of the works.

The issue that the current study is unable to unravel is whether this postoperative $\mathrm{PH}$ is residual, thus due to incomplete endarterectomy, recurrent, therefore due to relapse of CTEPH after complete endarterectomy, or persistent, due to coexistent small vessel disease instead. This further stratification of "residual" PH would greatly aide in understanding the pathophysiology of the disease and potentially lead toward more patient-specific treatment documented.

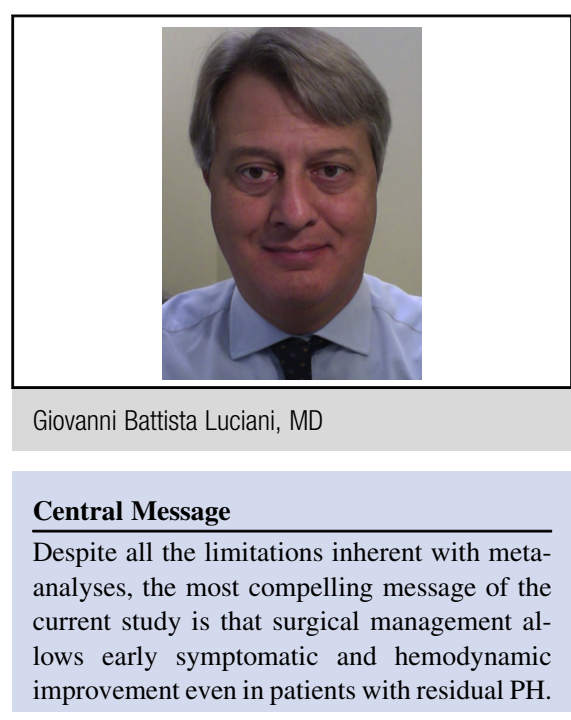

See Article page 1275.

strategies, particularly in light of the promising advancements in medical therapy. In fact, improved short-term survival has since been shown in patients with persistent $\mathrm{PH}$ after pulmonary endarterectomy using bosentan. ${ }^{3}$ Late outcome in these patients in terms of disease progression and complications inherent with long-term endothelin receptor antagonist therapy, however, remains to be

More recently, promising early results have been shown in terms of clinical and hemodynamic profile of patients with either inoperable or recurrent $\mathrm{PH}$ after pulmonary endarterectomy using riociguat, a guanylate cyclase stimulator. ${ }^{4}$ In addition, encouraging very early (16 weeks) hemodynamic outcomes have also been reported in these patients using the novel dual endothelin receptor antagonist mecitentan. ${ }^{5}$ Whether these findings will translate into durable improvement in functional capacity and, most importantly, in late survival remains to be seen.

Although some benefits of chronic medical therapy to alleviate hemodynamic burden of persistent $\mathrm{PH}$ and, possibly, to improve functional limitations of the disease may be expected based on recent literature, a plea for standardizing the definition of residual $\mathrm{PH}$ emerges from the present meta-analysis to reduce the heterogeneity and bias inherent with retrospective studies. Ultimately, the ability to stratify patients who combine chronic thromboembolic pulmonary artery obstruction with peripheral small vessel 
disease will help allocating patients to the most appropriate treatment, whether surgical, medical, or perhaps combined.

\section{References}

1. Hsieh WC, Jansa P, Huang WC, Nižnanský M, Omara M, Lindner J. Residual pulmonary hypertension after pulmonary endarterectomy: A meta-analysis. J Thorac Cardiovasc Surg. 2018;156:1275-87.

2. Bonderman D, Skoro-Sajer N, Jakowitsch J, Adlbrecht C, Dunkler D, Taghavi S, et al. Predictors of outcome in chronic thromboembolic pulmonary hypertension. Circulation. 2007;115:2153-8.
3. Hughes RJ, Jais X, Bonderman D, Suntharalingam J, Humbert M, Lang I, et al The efficacy of bosentan in inoperable chronic thromboembolic pulmonary hypertension: a 1-year follow-up study. Eur Respir J. 2006;28:138-43.

4. Ghofrani HA, D’Armini AM, Grimminger F, Hoeper MM, Jansa P, Kim NH, et al; CHEST-1 Study Group. Riociguat for the treatment of chronic thromboembolic pulmonary hypertension. $N$ Engl J Med. 2013;369:319-29.

5. Ghofrani HA, Simonneau G, D'Armini AM, Fedullo P, Howard LS, Jais X, et al MERIT study investigators. Macitentan for the treatment of inoperable chronic thromboembolic pulmonary hypertension (MERIT-1): results from the multicentre, phase 2, randomised, double-blind, placebo-controlled study. Lancet Respir Med. 2017;5:785-94. 